Khairullah Bin Anuar MBChB

Balwant Singh Gendeh MBBS, MS (ORL-HNS)

Department of Otorhinolaryngology Head and Neck Surgery

Universiti Kebangsaan Malaysia Medical Center

Cheras, Kuala Lumpur, Malaysia
Correspondence: Dr Khairullah Bin Anuar Department of Otorhinolaryngology

Medical Faculty, Universiti Kebangsaan Malaysia

Jalan Yaakub Latif

56000 Cheras, Kuala Lumpur

Malaysia

Phone: 603-91455555 ext 6838

Fax: 603-91737840

Email:khairullah4195@yahoo.co.nz

Reprints will not be available from the author.

The authors declared that this represents original material that is not being considered for publication or has not been published or accepted for publication elsewhere, in full or in part, in print or electronic media; that the manuscript has been read and approved by all the authors, that the requirements for authorship have been met by each author, and that each author believes that the manuscript represents honest work.

Disclosures: The authors signed disclosures that there are no financial or other (including personal) relationships, intellectual passion, political or religious beliefs, and institutional affiliations that might lead to a conflict of interest.

\section{Tube Extrusion and Cheese Wiring Five Years Post Dacryocystorhinostomy}

\begin{abstract}
Objective: Dacrocystorhinostomy (DCR) with silicone tube stenting is a common procedure for congenital nasolacrimal duct obstruction (NLDO). The incidence of congenital NLDO is about $6 \%$ in the newborn. The duration the tube is left in place varies depending on surgeon preference. Cheese wiring is one of the tube-related complications when the tube is left behind for a long duration. The term cheese wiring refers to the silicone stent or tubing cutting through soft tissue close to the punctum or canaliculi like wire cuts through cheese. We present a case of tube extrusion with cheese wiring five years post DCR.
\end{abstract}

\section{Methods:}

\author{
Design: Case report \\ Setting: Tertiary Referral Center \\ Patient: One
}

Results: A 16-year-old Indian male with congenital bilateral NLDO underwent right and left DCR at ages 9 and 11, respectively. The patient presented with smelly nasal discharge five years later to the ENT clinic. On initial examination the right tube was in place but the left tube was not visualized. Nasal endoscopy however revealed that both tubes were still there and were subsequently removed.

Conclusion: DCR with silicone intubation is a common practice. Early follow up is essential to prevent complications. If tube extrusion is suspected, early endoscopic examination is essential to confirm it.

Keywords: nasolacrimal duct obstruction, dacrocystorhinostomy, tube extrusion, cheese wiring

Dacrocystorhinostomy (DCR) with silicone tube stenting is a common procedure for congenital nasolacrimal duct obstruction after failed conservative management including lacrimal apparatus probing and irrigation. The incidence of congenital nasolacrimal duct obstruction (NLDO) is about $6 \%$ in the newborn. ${ }^{1}$ The duration the tube is left in place varies depending on surgeon preference, from several weeks up to more than 12 months. Cheese wiring is one of the complications when the tube is left behind for a long duration. We report a case of cheese wiring five years post $D C R$. 


\section{CASE REPORT}

A 16-year-old Indian male presented with history of bilateral epiphora associated with yellowish discharge since birth. He had previous probing and syringing under general anaesthesia in 2002 and early 2003 at the age of 8 years and 9 years, respectively. A dacrocystogram (DCG) in April 2003 showed complete obstruction at the right lacrimal sac and left inferior canaliculus. An ophthalmologist performed right external dacrocystorhinostomy (DCR) with bordeaux tube in September 2003 and left external DCR with bordeaux tube in 2005. On subsequent visits to the outpatient eye department it was thought that the left tube was dislodged. An ENT referral was made for occasional epistaxis and smelly nasal discharge of two months duration. On examination of the eye, the right bordeaux tube was in situ (Figure 1). However on the left eye, the tube could not be visualized with evidence of cheese wiring of the

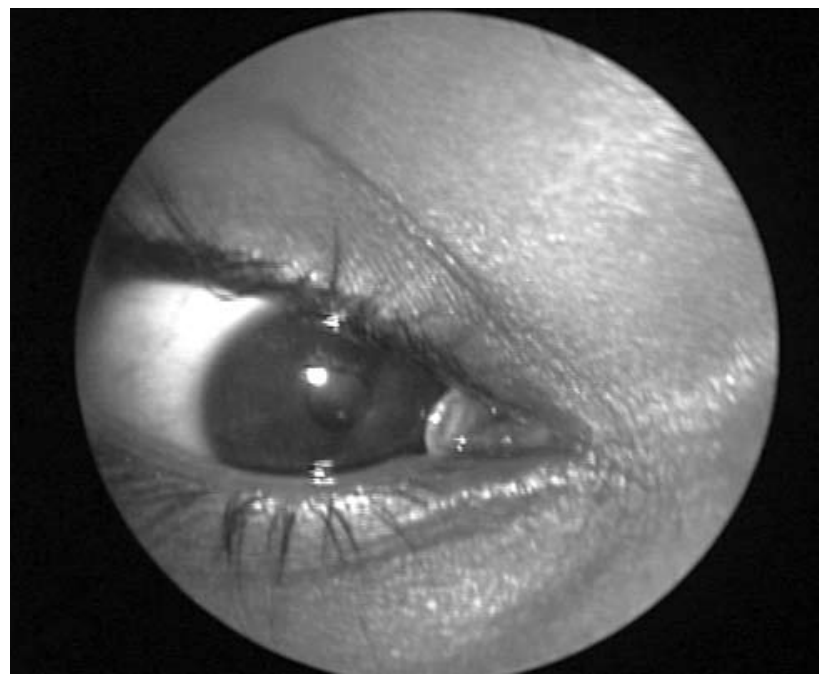

Figure 1. Right eye, tube in situ

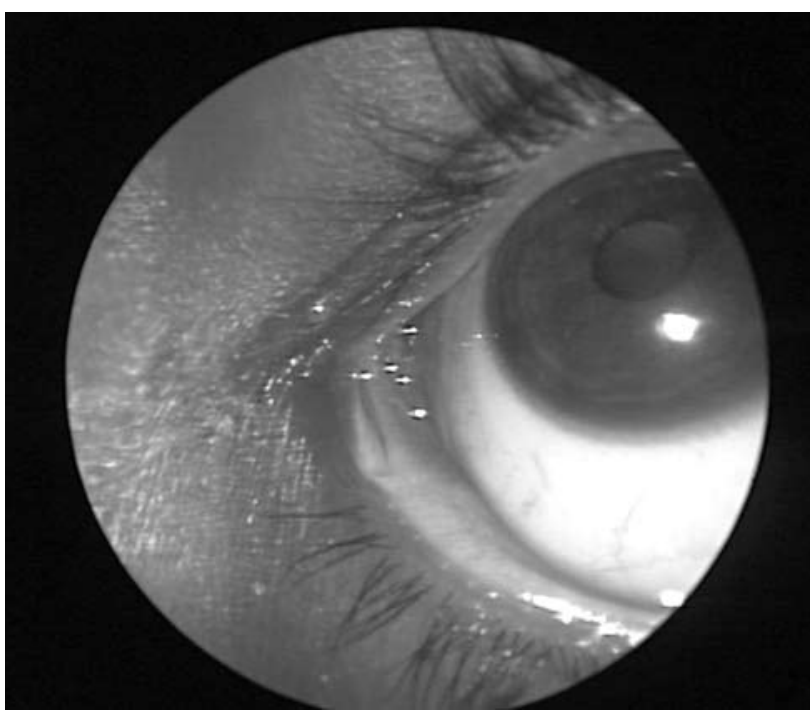

Figure 2. Left eye cheese wiring inferior canaliculus (Figure 2). Endoscopic examination revealed that the tubes were covered with greenish encrusted secretions (Figures $3 \& 4$ ). Both tubes were removed (Figures $5 \& 6$ ). The patient was treated with an oral antibiotic, intranasal steroid and oral antihistamine. On follow up at three months, there was no more epiphora or evidence of foul smelly discharge or epistaxis. Clinically he had a patent canaliculus with no mucopus or polyp seen.

\section{DISCUSSION}

Obstruction of the nasolacrimal duct results in disturbed outflow of tears, commonly known as epiphora. Although epiphora is a benign condition, it has social implications. Adeo Toti introduced an operation which he called dacryocystorhinostomy (DCR) for the treatment of epiphora. ${ }^{2}$ After creating an external approach to the lacrimal

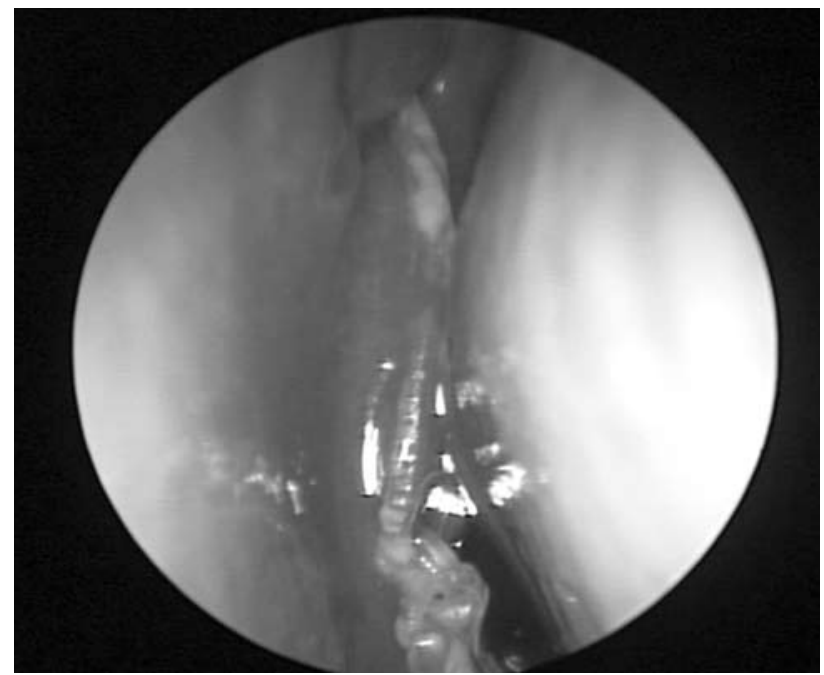

Figure 3. Right nasoendoscopic view, tube in situ

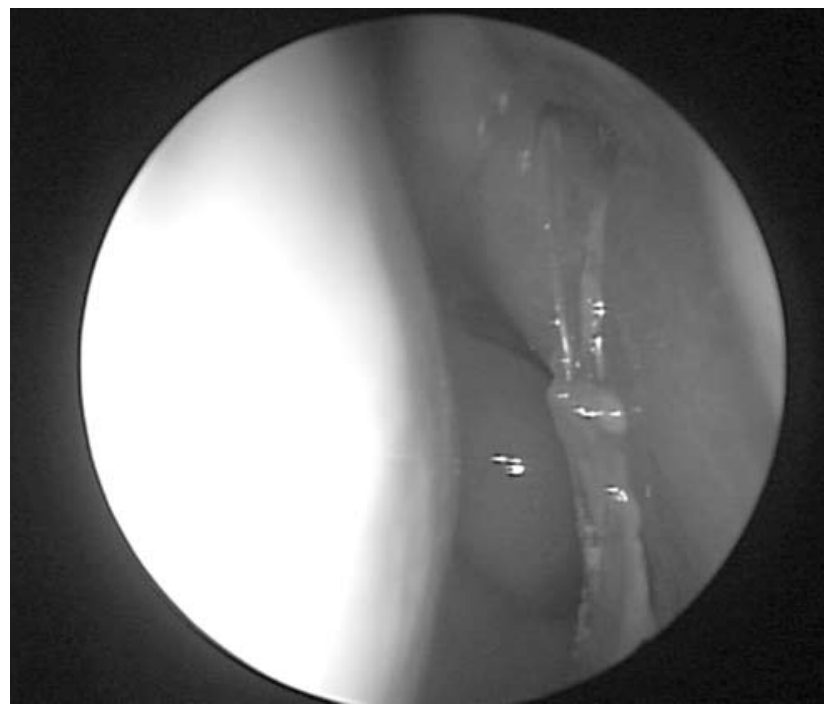

Figure 4. Left nasoendoscopic view, tube in situ 


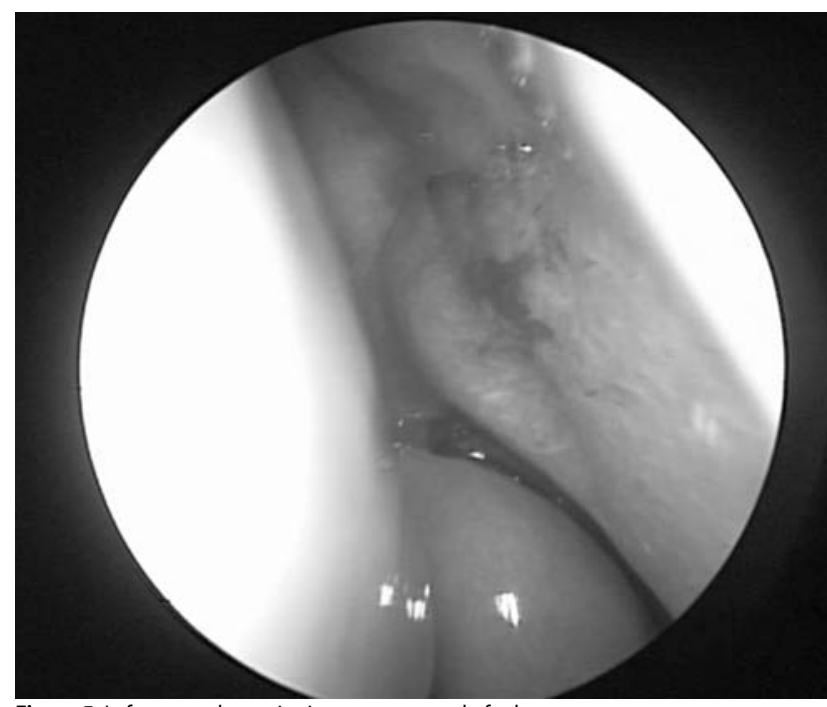

Figure 5. Left nasoendoscopic view, post removal of tube

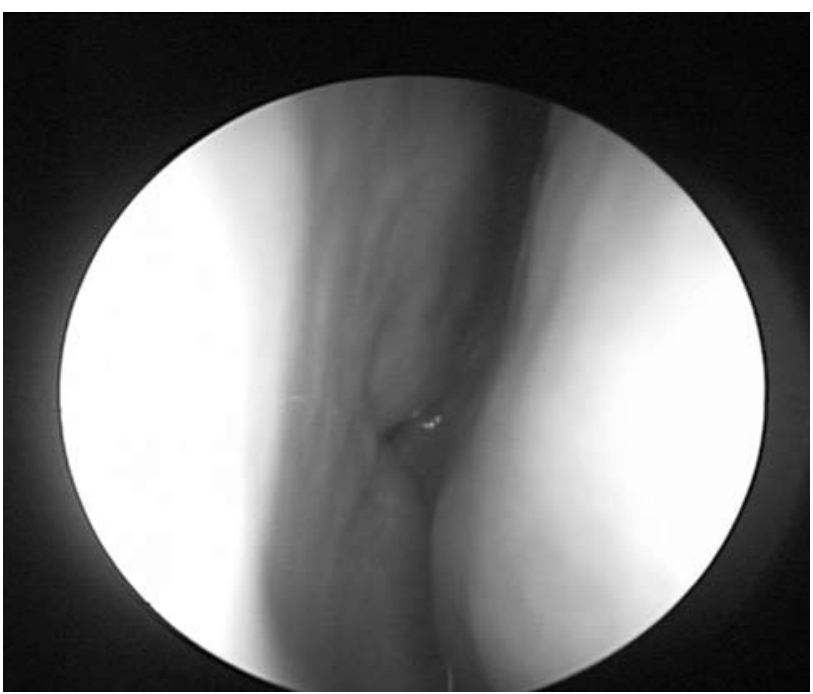

Figure 6. Right nasoendoscopic view, post removal of tube

sac, its portion near the canaliculi should be preserved and absorbed into the nose by creating a window in the lateral wall of the nose. An endonasal approach was introduced by Caldwell in $1893 .{ }^{3}$ Its use was initially limited by the difficulty of visualizing endonasal structures during surgery. The development of operating microscopes and subsequent rigid endoscopes aroused more interest for the endonasal approach. Powered endoscopic DCR was subsequently popularized by PJ Wormald. ${ }^{4}$

The current gold standard for treating epiphora by ophthalmologists is external DCR. Beginning in the 1970's, surgeons began to favour DCR with intubation tubes over DCR without intubation tubes. ${ }^{5} \mathrm{~A}$ recent survey of ophthalmologists in the UK showed that the insertion of silicone tubes for external DCR was routine. ${ }^{6}$ For congenital NLDO, DCR with nasolacrimal silicone tube intubation is the treatment of choice after failed probing and irrigation. ${ }^{7}$ The necessity of intubation in DCR remains controversial even though its use is common practice. Some studies found that silicone intubation improves success rates in children while other studies showed no difference in outcome .,8 $^{7}$

The time frame for silicone tube removal varied in the literature from as early as 3 to 7 weeks to as late as over a year. ${ }^{3,9}$ Charalampidou et al. reviewed a retrospective study of external DCR and found that out of 180 cases, 94 tubes were removed between 2 to 4 months, 24 tubes were removed before the planned 2 - month period and 62 tubes were removed after the 4 month period. ${ }^{10}$ The survey of ophthalmologists also found out that the tubes were removed as early as 4 weeks. ${ }^{6}$

Complications of silicone tube insertion include marsupialization of canaliculi, granuloma formation, corneal abrasion, fistula formation, chronic mucopurulent discharge and nasal irritation. Punctal and canalicular complications include punctal stretch, erosion and cheese wiring. The incidence of cheese wiring has been reported to be $2.6 \%$ for external DCR and $1.5 \%$ for endoscopic DCR. ${ }^{2}$ The etiology of cheese wiring results from the tube being placed under tension and left behind for a long duration. Another possible explanation for cheese wiring is that wiping the eye when the eyelids are closed, the stent loop is immobilized such that outward wiping of the eyelid pulls the punctum against the fixed stents. Other causes of cheese wiring may include unintentional trauma during probing or chronic irritation from the tube itself. ${ }^{11}$

In this case the patient had congenital NLDO and needed a longer time for tube placement which may have resulted in migration of the tube and cheese wiring. Charalampidou et al. suggested for early review of the tube within a week and anticipation of cheese wiring if the tubes were too tight. ${ }^{10}$ In such cases, early follow up is essential to prevent complications. If tube extrusion is suspected, early endoscopic examination is essential to confirm it.

\section{REFERENCES}

1. Charmaine SL, Martin F, Beckenham T, Cumming RG .Nasolacrimal duct obstruction in children: outcome of intubation. J American Association for Pediatric Opthalmology and Strabismus. 2004 Oct; 8(5):466-472.

2. Dolman PJ. Comparison of external dacrocystorhinostomy with non laser endonasal dacrocystorhinostomy. Ophthalmology 2003 Jan;110(1):78-84.

3. Onerci M. Diagnosis and treatment of nasolacrimal canal obstructions. Rhinology. 2002 June; 40 (2):49-65.

4. Wormald PJ. Powered endonasal dacryocystorhinostomy. Laryngoscope. 2002 Jan;112(1):69-71

5. Saiju R, Morse LJ, Weinberg D, Shrestha MK, Ruit S. Prospective randomized comparison of external DCR with and without silicone intubation. Br J Opthalmol. 2009 June; 93(9.):12201222.

6. Gauba V. The practice of dacryocystorhinostomy (DCR) surgery by ophthalmologists in the United Kingdom (UK). Orbit. 2008 Jan; 27(4):279-83.

7. Nemet AY, Fung A, Martin PA, Benger R, Kourt G, Danks JJ et al. Lacrimal drainage obstruction and dacryocystorhinostomy in children. Eye. 2008 July; 22 (7):918-24.

8. Kashkouli MB, Parvaresh M, Modarreszadeh M, Hashemi M, Beigi B. Factors affecting the success of external dacryocystorhinostomy. Orbit. 2003 Dec; 22(4):247-55.

9. Hartikainen J, Gremnan R, Puukka P, Seppä H. Prospective randomized comparison of external dacryocystorhinostomy and endonasal laser dacryocystorhinostomy. Ophthalmology. 1998 June; 105(6):1106-13.

10. Charalampidou $\mathrm{S}$, Fulcher T. Does the timing of silicone tube removal following external dacryocystorhinostomy affect patients' symptoms? Orbit. 2009 April; 28 (2):115-119.

11. Anderson RL, Edwards JJ. Indications, complications and results with silicone stents. Ophthalmology .1979 Aug; 86(8): 1474-87. 